\title{
Synergistic improvement of mechanical and magnetic properties of a new magnetorheological elastomer composites based on natural rubber and powdered waste natural rubber glove
}

\author{
Nabil Hayeemasae ${ }^{1 *}$ (D) and Hanafi Ismail ${ }^{2}$ \\ 'Department of Rubber Technology and Polymer Science, Faculty of Science and Technology, Prince of \\ Songkla University, Pattani Campus, Pattani, Thailand \\ ${ }^{2}$ School of Materials and Mineral Resources Engineering, Engineering Campus, Universiti Sains \\ Malaysia, Nibong Tebal, Penang, Malaysia \\ *nabil.h@psu.ac.th
}

\begin{abstract}
Recycling of rubber waste and finding the effective methods to extend its use are one of major challenges nowadays. In the present study, waste natural rubber glove (wNRg) was used in an attempt to extend its use and create a value-added composite based on natural rubber (NR) and wNRg. Another interesting focus was to develop such material into a new Magnetorheological Elastomer (MRE). This MRE can be prepared by incorporating Ferromagnetic particles namely carbonyl iron (CI) to the rubber composite. Carbon black (CB) was also added to obtain MRE with remarkably mechanical properties. CI was fixed at $60 \mathrm{phr}$ where the $\mathrm{CB}$ was varied from $10-30 \mathrm{phr}$. Higher thermal conductivity and magneticity in nature of CI had made the composites faster cure and higher magnetic strength. On the contrary, superior tensile strength, modulus and elongation at break were found in the presence of $\mathrm{CB}$. From the experimental results, hybridization of $60 / 10 \mathrm{phr} / \mathrm{phr}$ of CI and $\mathrm{CB}$ is highly suggested to gain the synergistic strength and magneticity. This is expected to solve a big problem in the application of MRE.
\end{abstract}

Keywords: natural rubber, carbonyl iron, carbon black, magnetic properties.

How to cite: Hayeemasae, N., \& Ismail, H. (2020). Synergistic improvement of mechanical and magnetic properties of a new magnetorheological elastomer composites based on natural rubber and powdered waste natural rubber glove. Polimeros: Ciência e Tecnologia, 30(2), e2020020. https://doi.org/10.1590/0104-1428.10719

\section{Introduction}

Smart materials is an intelligent or responsive materials that have one or more properties simultaneously by changing external stimuli, such as stress, moisture, electric or magnetic fields, light, temperature, $\mathrm{pH}$, or chemical compound. There are many types of smart materials available in our daily life. Magnetorheological elastomer (MRE) is also one of them ${ }^{[1,2]}$. MRE can be fluid, gel or even a solid material such as elastomer. This kind of elastomer material offers multiple advantages as compared to conventional rubber materials. MRE is prepared by incorporating magnetically permeable particles (ferromagnetic filler) ${ }^{[3]}$ into a non-magnetic matrix which is the rubber matrix. The bahaviors of magnetic particles depends on the methods of fabrication. Isotropic MRE refers to the MRE containing a uniform suspension of magnetic particles whereas Anisotropic MRE is found when a magnetic field is applied during curing where chain-like structures of magnetic particles are formed in this stage ${ }^{[4,5]}$.

Recently, there are several types of ferromagnetic fillers that are used to prepare MRE. Each of them possesses its own advatanges depending on the density, size and shape. The examples of magnetic particles are carbonyl iron, magnetite, iron oxides, barium ferrite and so forth ${ }^{[6-8]}$. Among them, carbonyl iron (CI) seems to provide excellent properties to $\mathrm{MRE}^{[9]}$. CI is spherical in shape and has some advantages when using as ferromagnetic particles. These include high magnetic susceptibility, high magnetic saturation, high inter-particle interaction forces and low remnant magnetization required for quick and reversible control in MRE applications ${ }^{[10-12]}$

At the present time, the effects of individual fillers on the properties of composites are relatively well-known ${ }^{[13]}$. As for example, the use of carbonyl iron for producing magnetoelastomer generally provides excellent magnetic properties. However, the mechanical properties cannot usually be improved by such filler. The idea of using a hybrid filler comprised of two or more traditional filler materials has already been explored in the literature. This approach has been demonstrated to provide great performance to the rubber vulcanizate. Therefore, synergistic advantages can be achieved by combining such fillers. Carbon black (CB) is again the filler of chioce to be used as hybrid filler especially in the composite where non-reinforcing filler 
has been originally incorporated. The carbon black consists wide variety of grades depending on their size, surface area and structures. The commercial carbon blacks are spherical particles with diameters of the order $15-50 \mathrm{~nm}$ and tend to exist in fused chainlike agglomerates which are referred to as the structure ${ }^{[14]}$. The presence of carbon black in vulcanized rubber enormously enhances the tensile strength, elastic modulus, and abrasion resistance.

So far, MRE has been prepared from many types of rubber matrices both general propose and specialty rubbers. For examples, natural rubber, silicone rubber, polybutadiene, polyisobutylene, polyisoprene and polyurethene rubber ${ }^{[15-18]}$. However, none of them has been designed to develop new MRE from waste natural rubber. In this study, natural rubber (NR) and waste natural rubber glove (wNRg) were used as matrices in association with a combination of high magnetic filler $(\mathrm{CI})$ and high reinforcing filler (CB). By varying the volume fraction of hybrid fillers, a new kind of value-added rubber composites with simultaneous improvement of magnetic and mechanical properties are developed. CI possesses a very high magnetic strength but not compatible to the natural rubber. This is not happened when incorporating CB to the natural rubber. CI may affect the magnetic properties to the rubber matrices. Thus, MRE can be prepared successfully. In the meantime, the mechanical properties can be modified through hybridization with CB. The work described here was part of a broader study aimed at developing a class of inexpensive MRE with good mechanical properties. It is a preliminary investigation to determine whether or not significant mechanical improvements could be achieved using readily accessible, relatively cheap commercial filler. It is expected that the results obtained in this study will be of importance for new MRE of further increasing of working frequency and miniaturization of materials that required these two properties.

\section{Materials and Methods}

\subsection{Materials}

The natural rubber (NR) used was SMR L grade, which was obtained from Mardec Sdn. Bhd., Malaysia. Waste natural rubber glove (wNRg) was supplied by Juara One Resources Sdn. Bhd., Malaysia. The wNRg was crushed into a size range from $100-500 \mu \mathrm{m}$ using Table Type Pulverizing Machine from Chyun Tseh Industrial Co. LTD, Taiwan. Carbon Iron (CI) powder was purchased from Sigma Aldrich (M) Sdn. Bhd., Malaysia. The carbon iron was in spherical shapes as seen in Figure 1 and the particle size is ranging from $0.7-1.0 \mu \mathrm{m}$. Other compounding ingredients such as N330 grade carbon black (CB), Zinc oxide, Stearic acid, Vulkanox BKF, N-cyclohexyl-2-benzothiazole sulfonamide (CBS) and Sulfur were purchased from Bayer (M) Sdn. Bhd., Malaysia.

\subsection{Preparation of $\mathrm{Cl} / \mathrm{CB}$ hybrid filled NR/wNRg composites}

Table 1 shows the ingredients used in the $\mathrm{CI} / \mathrm{CB}$ hybrid filled NR/wNRg composites. Before the compounding process, the $\mathrm{CI}$ powder was dried using oven at $80^{\circ} \mathrm{C}$ for 3 hours to expel the moisture. Then, the entire amount of ingredients was compounded on a laboratory size two roll mill model XK-160. The mixing procedure followed ASTM D3182 and the sequence followed the order arranged in the formula. Later, the compounds were kept in the freezer for conditioning and the compounds were finally compression molded into specific shapes by a hydraulic hot press, using the curing times determined by a Moving Die Rheometer (MDR).

\subsection{Measurement of curing characteristics}

The curing characteristics of the composites were obtained by using MDR 2000 (Alpha Technologies, USA), which was used to determine torques, scorch time $\left(\mathrm{ts}_{2}\right)$ and curing time $\left(\mathrm{tc}_{90}\right)$ according to ASTM D5289. Samples of the respective compounds were tested at $150^{\circ} \mathrm{C}$.

\subsection{Measurement of mechanical properties}

Dumbbell-shaped samples were cut from the molded sheets according to ASTM D412, and tensile tests were performed at a cross-head speed of $500 \mathrm{~mm} / \mathrm{min}$. The tensile tests were carried out with Instron Universal Testing Machine, model 3366 , to determine $100 \%$ modulus, $300 \%$ modulus, tensile strength and elongation at break. As for tear strength, the crescent shape test pieces or type $\mathrm{C}$ test pieces were cut out according to ASTM D624. The tear test was carried out using the same machine and setting up.

\subsection{Scanning electron microscopy}

The fractured surfaces obtained from tensile and tear test were used to capture the morphological characteristics of $\mathrm{CI} / \mathrm{CB}$ hybrid filled NR/wNRg composites. The fractured

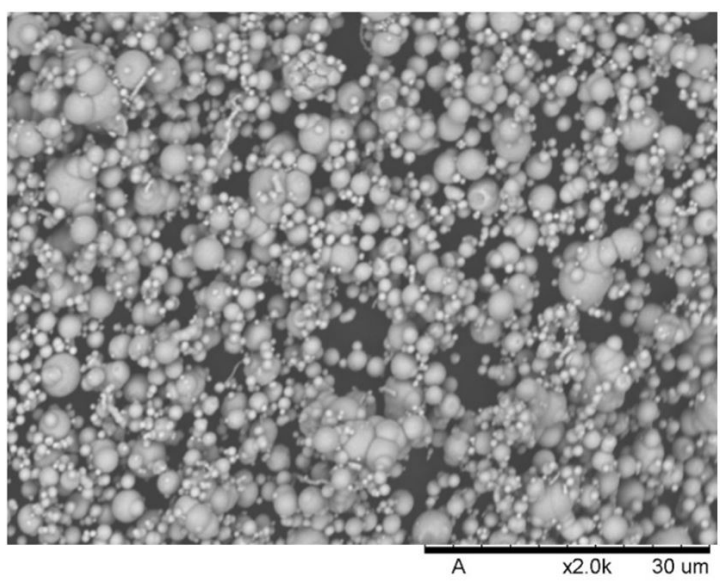

Figure 1. SEM Micrograph of carbonyl iron used in this study ${ }^{[19]}$.

Table 1. Compounding formulation of the $\mathrm{CI} / \mathrm{CB}$ hybrid filled NR/wNRg composites ${ }^{[19]}$.

\begin{tabular}{lc}
\hline \multicolumn{1}{c}{ Ingredient } & Amount (phr) \\
\hline SMR L & 50 \\
Waste NR Glove & 50 \\
ZnO & 5 \\
Stearic Acid & 3 \\
BKF & 1 \\
CI & 60 \\
Carbon Black (N330) & $0,10,20 \& 30$ \\
CBS & 1 \\
Sulfur & 2.5 \\
\hline
\end{tabular}


pieces were coated with a layer of gold palladium to eliminate electrostatic charge buildup during examination. The observations were performed using a Supra-35VP Field Emission and Quanta 400 Scanning Electron Microscope (FESEM).

The geometry of the CI was determined using Tabletop Microscope TM3030 (see Figure 1). A double sided tape was applied on the mold plate. Then, the mold plate with tape was dipped into the powder of CI. After that, the mold plate was inserted into the tabletop SEM to carry out morphological analysis.

\subsection{Swelling behaviour and crosslink density}

Swelling uptake was done according to ASTM D471. The vulcanized samples with dimension of $30 \mathrm{~mm} \times 5 \mathrm{~mm} \times 2 \mathrm{~mm}$ were weighed before being swollen in toluene until equilibrium, which took approximately 72 hours at room temperature. The samples were taken out from the toluene, wiped off and finally weighted before calculation based on the Equation 1.

$$
\text { Swelling }=\frac{\left(W_{2}-W_{1}\right)}{W_{1}} \times 100
$$

where $W_{1}$ and $W_{2}$ is the mass (g) of samples before and being swollen respectively. The swelling outputs were further applied to calculate the molecular weight between crosslinking points $\left(M_{C}\right)$ and crosslink density $\left(V_{C}\right)$ through the Flory-Rehner Equation (see Equations 2 and 3) ${ }^{[20]}$.

$$
\begin{aligned}
& M_{c}=\frac{-\rho_{p} V_{s} V_{r}^{1 / 3}}{\ln \left(1-V_{r}\right)+V_{r}+\chi V_{r}^{2}} \\
& V_{r}=\frac{1}{1+Q_{m}}
\end{aligned}
$$

where $\rho$ is the density of rubber (NR and wNRg) which is equal to 0.92 and $0.94 \mathrm{~g} / \mathrm{cm}^{3}$ respectively, $V_{S}$ is the molecular volume of toluene which is $106.4 \mathrm{~cm}^{3} / \mathrm{mol}, V_{R}$ is the volume fraction of rubbers in the swollen sample, $Q_{M}$ is the mass increase of the samples after swelling and $\chi$ is the interaction parameter of the rubber network and toluene ( $\chi$ of NR or wNRg is 0.393 ). The degree of crosslink density $\left(V_{C}\right)$ is given below;

$$
V_{c}=\frac{1}{2 M_{c}}
$$

\subsection{Magnetic property}

The magnetic flux density or magnetic induction of the MRE samples were measured using a hand type gaussmeter with the probe connected to the Tesla Meter, model TM-801AXL (Axial Probe). This axial probe was brought into direct contact with the vulcanized rubber sheet to measure the magnetic flux density in the axial direction. The rubber sheets were magnetized using a magnet with approximate 200 millitesla $(\mathrm{mT})$ prior to be tested. The probe was placedseveral points and recorded.

\section{Results and Discussions}

\subsection{Curing characteristics}

Table 2 shows the curing characteristics of $\mathrm{CI} / \mathrm{CB}$ hybrid filled NR/wNRg composites. The scorch time $\left(\mathrm{ts}_{2}\right)$ decreased gradually with increasing $\mathrm{CB}$ loading. The result of scorch time obtained from graph was $2.21 \mathrm{~min}, 1.85 \mathrm{~min}, 1.6 \mathrm{~min}$ and $1.53 \mathrm{~min}$ for $0 \mathrm{phr}$, $10 \mathrm{phr}, 20 \mathrm{phr}$ and $30 \mathrm{phr}$ respectively. This is indicated that $\mathrm{CB}$ facilitates the formation of crosslinks in the vulcanization process. Such finding is responsible to the heat history of the rubber compounds. Medalia et al. ${ }^{[2]]}$ reported that $\mathrm{CB}$ can cause to delay the total mixing time of rubber compounding, consequently more heat was generated due to the additional friction. This has brought to take shorter time to reach the onset of vulcanization. On the other hand, the curing time $\left(\mathrm{tc}_{90}\right)$ is inversely found for the $\mathrm{CI} / \mathrm{CB}$ filled $\mathrm{NR} / \mathrm{wNRg}$ composites. It gives a longer trend upon the addition of $\mathrm{CB}$. This is a clear indication that the time taken to complete the vulcanization depends strongly on the presence of CI. More heat transfer occurs in the presence of CI. CI possesses the thermal conductivity value of $0.1922 \mathrm{cal} / \mathrm{cm} \cdot \mathrm{sec}^{\circ} \mathrm{C}^{[22]}$. This value is way bigger than the thermal conductivity of $\mathrm{CB}$ which is about $0.00067 \mathrm{cal} / \mathrm{cm} \cdot \mathrm{sec}^{\circ} \mathrm{C}^{[23,24]}$. Even though the $\mathrm{CB}$ also provide the thermal conductive characteristics but higher amount of $\mathrm{CB}$ can restrict the thermal conductive pathway of CI unlike the composites with solely CI. This makes the heat transfer less efficient to the rubber chain and takes longer time to complete the vulcanization process.

The torque difference $\left(\mathrm{M}_{\mathrm{H}}-\mathrm{M}_{\mathrm{L}}\right)$ is a measure of the difference between stiffness or shear modulus of the fully vulcanized and unvulcanized test specimens taken at the lower point of the vulcanizing curve. The $M_{H}-M_{L}$ was found to increase with increasing CB loading. The increment of the $M_{H}-M_{L}$ was due to the presence of $\mathrm{CB}$, which has a higher restriction to molecular motion of the macromolecule or tends to increase resistance to flow ${ }^{[25]}$. Regarding to such positive finding, it can be verified that these properties are dependent on the $\mathrm{CB}$ content. $\mathrm{CB}$ has a smaller particle size and higher surface activity, as well as higher structure, in comparison to CI powder. This may have improved the rubber-filler interactions. Wolff and Wang ${ }^{[2]]}$ reported that $\mathrm{M}_{\mathrm{H}}-\mathrm{M}_{\mathrm{L}}$ depends on the crosslink density and chain entanglement and may also be dependent on the $\mathrm{CB}$, which has a higher structure than other fillers, thus resulting in the NR molecular chains being more easily trapped and occluded in the voids of the $\mathrm{CB}$ aggregates. Increasing the amount of occluded rubber increased the effective concentration of the $\mathrm{CB}$ aggregates in the rubber and decreased the fluidity of the gross rubber during the mixing process as well. Hence, higher values of torque difference occurred when increasing $\mathrm{CB}$ content in the composites.

Table 2. Curing characteristics of CI/CB hybrid filled NR/wNRg composites $^{[19]}$.

\begin{tabular}{cccc}
\hline $\begin{array}{c}\text { CI/CB } \\
\text { Content } \\
\text { (phr/phr) }\end{array}$ & $\mathbf{M}_{\mathbf{H}}-\mathbf{M}_{\mathbf{L}}$ (d.Nm) & $\mathbf{t s}_{\mathbf{2}}$ (min) & $\mathbf{t}_{\mathbf{9 0}}$ (min) \\
\hline $60 / 0$ & 9.04 & 2.21 & 5.42 \\
$60 / 10$ & 11.01 & 1.85 & 5.43 \\
$60 / 20$ & 13.1 & 1.6 & 5.68 \\
$60 / 30$ & 15.35 & 1.53 & 6.43 \\
\hline
\end{tabular}




\subsection{Mechanical properties}

Figure 2 presents the tensile strength and elongation at break of $\mathrm{CI} / \mathrm{CB}$ hybrid filled NR/wNRg composites. The tensile strength improved up to $10 \mathrm{phr}$ of $\mathrm{CB}$, but above this level the strength was reduced. CB has a very unique structure and high aspect ratio, so it is frequently combined with various rubbers to increase the mechanical strength of composites. The particle size of $\mathrm{CB}$ is very small compared to $\mathrm{CI}$, hence resulting in strong interfacial interaction in the rubber matrix. Another probable reason might be due to the surface chemistry of $\mathrm{CB}$ which is more compatible to the rubber matrix. This could make the $\mathrm{CB}$ disperse well in rubber matrix and lead to improved stress transfer in the rubber matrix. Similar trend was also found for the elongation at break of the composites, indicating that better interfacial interaction of $\mathrm{CB}$ and rubbers can prolong the breaking strain which then improved the elasticity of the rubber composites.

The reduction in tensile strength and elongation at break with loadings beyond $10 \mathrm{phr}$ of $\mathrm{CB}$ is simply due to the dilution effect. When more $\mathrm{CB}$ is integrated into the rubber matrix, the $\mathrm{CB}$ particles tend to interact with each other, known as filler-filler interactions or aggregation of $\mathrm{CB}$, which is seen in the SEM micrographs later. It can be seen that the stresses at $100 \%$ and $300 \%$ elongations (M100, M300) increased significantly with CB loading (see Table 3). As more CB gets into the rubber; the total amount of fillers is high, the elasticity of the rubber is then reduced, resulting in more rigid, stiffer and harder composites. This is in good agreement with the crosslink density reported in the next section.

The tear strength of CI/CB hybrid filled NR/wNRg composites is shown in Figure 3. Tear strengths of the composites are shown different trend as compared to tensile strength and elongation at break. It can be seen that the addition of $\mathrm{CB}$ to the hybrid system had increased the tear strength upwards. This is simply due to the nature of $\mathrm{CB}$ itself which has already mentioned in the previous results. Since the tensile and tear tests are not similar, the optimum loading of $\mathrm{CB}$ to give optimum properties of each tensile and tear strengths are not the same. Therefore, higher energy was required to cause the tearing failure upon the use of $\mathrm{CB}$ in the hybrid system.

\subsection{Swelling uptake}

The swelling uptake and corresponding crosslink density of CI/CB hybrid filled NR/wNRg composites are also listed in Table 3. The swelling percentage was investigated by toluene uptake until equilibrium swelling was reached at room temperature. It is well-established that swelling resistance correlates to the crosslink density in a network chains ${ }^{[27]}$. Low swelling uptake indicates higher crosslink density. The swelling percentages decreased with increasing $\mathrm{CB}$ loading. The highest swelling percentage is at $0 \mathrm{phr} \mathrm{CB}$ where the value is about $187.51 \%$. Then it was decreased with increasing CB loading at $162.98 \%, 134.78 \%$ and $122.03 \%$. for $10-30 \mathrm{phr}$ of $\mathrm{CB}$ respectively. The presence of $\mathrm{CB}$ has brought to a strong interfacial interaction. As a consequence, less penetration of toluene is observed upon inclusion of $\mathrm{CB}$.

Despite being due to the reduction of the free volume in the vulcanizate, $\mathrm{CB}$ also affects the crosslinking efficiency of the rubber. As reported by Baccaro et al. ${ }^{[28]}$, they have explained that $\mathrm{CB}$ enables to involve both physical and chemical crosslinks. A physical entrapment is due to the interactions between rubber chains and microstructure defects and surface porosity of $\mathrm{CB}$. While, the chemical crosslinks are associated to the electron acceptors on the surfaces of rubber macroradicals and CB during mixing. This has brought to an increase in crosslink density in the presence of CB.

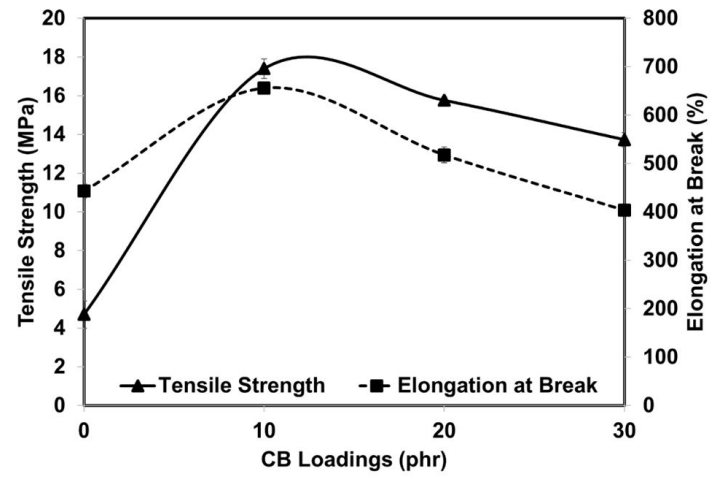

Figure 2. Tensile strength and elongation at break of $\mathrm{CI} / \mathrm{CB}$ hybrid filled NR/wNRg composites.

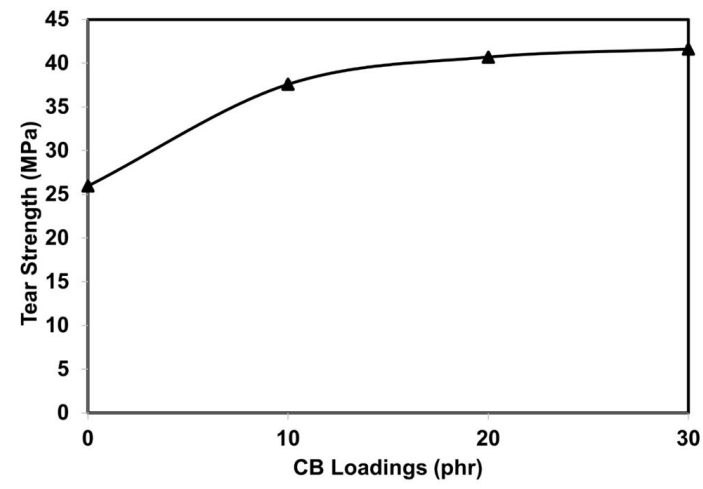

Figure 3. Tear strength of CI/CB hybrid filled NR/wNRg composites.

Table 3. Tensile modulus, swelling uptake and crosslink density of $\mathrm{CI} / \mathrm{CB}$ hybrid filled NR/wNRg composites.

\begin{tabular}{|c|c|c|c|c|}
\hline \multirow{2}{*}{ CI/CB hybrid content (phr/phr) } & M100 & M300 & Swelling & Crosslink density \\
\hline & (MPa) & (MPa) & $(\%)$ & $\left(\times 10^{-5} \mathrm{~mol} / \mathrm{cm}^{3}\right)$ \\
\hline $60 / 0$ & $1.14 \pm 0.034$ & $2.66 \pm 0.011$ & $187.51 \pm 2.22$ & $1.51 \pm 0.55$ \\
\hline $60 / 10$ & $1.71 \pm 0.012$ & $4.63 \pm 0.033$ & $162.98 \pm 3.29$ & $2.18 \pm 0.35$ \\
\hline $60 / 20$ & $2.52 \pm 0.025$ & $7.14 \pm 0.015$ & $134.78 \pm 4.55$ & $2.48 \pm 0.42$ \\
\hline $60 / 30$ & $3.30 \pm 0.031$ & $9.51 \pm 0.018$ & $122.03 \pm 5.78$ & $2.97 \pm 0.19$ \\
\hline
\end{tabular}




\subsection{Morphology of fracture surface analysis}

Figure 4 illustrates the tensile fractured surfaces of $\mathrm{CI} / \mathrm{CB}$ hybrid filled NR/wNRg composites at 500× magnifications. As for the control sample ( 0 phr of CB), some detachment of $\mathrm{CI}$ is visible, showing many voids, loose, and agglomeration of CI particles on the fractured surface. This indicates a weak rubber-filler interaction. The presence of voids on the samples leads to localize the stress concentration during deformation. Thus, premature failure of $\mathrm{CI} / \mathrm{CB}$ hybrid filled NR/wNRG composites occurred. However, surface roughness of the fractured surfaces was more visible when the $\mathrm{CB}$ was used as hybrid filler due to better rubber-filler interaction take place. Comparing the composites at 20 and $30 \mathrm{phr}$ of $\mathrm{CB}$, they reveal how roughness and the tortuous path of the fractured surface increased when $\mathrm{CB}$ was further used. The occurrence of these two failure samples are more towards difficult manner compared to the composites with the $\mathrm{CI}$ alone, resulted in a higher tensile strength. This observation can be visibly seen after adjusting the contrast between the voids (black) and tearing pathways (white) of the composites. The voids formation is towards smaller size when increasing the $\mathrm{CB}$ loadings, indicating that $\mathrm{CB}$ can enhance the distribution of $\mathrm{CI}$ throughout the rubber matrices. As a result, higher strength is found upon inclusion of $\mathrm{CB}$

Figure 5 displays the tear fractured surfaces of $\mathrm{CI} / \mathrm{CB}$ hybrid filled NR/wNRg composites at 500× magnification. Based on the SEM images, there are some explanation can be made. Typical image was found for CI filled NR/wNRg composite ( $0 \mathrm{phr}$ of $\mathrm{CB})$. With the addition of $10 \mathrm{phr}$ of CB, the failure surfaces show feature of well-developed interfacial interaction. An augmentation in surface roughness and a homogeneous pattern are more pronounced when more $\mathrm{CB}$ was incorporated as hybrid filler, indicating a coherence of the $\mathrm{CB}$ particles and the rubber phases. It is interesting to highlight that, for the addition of $30 \mathrm{phr}$ of $\mathrm{CB}$, there were a few voids on the fractured surface (see the black areas in the monochrome images provided). This showed that it was a strong interfacial adhesion between phase occurred.

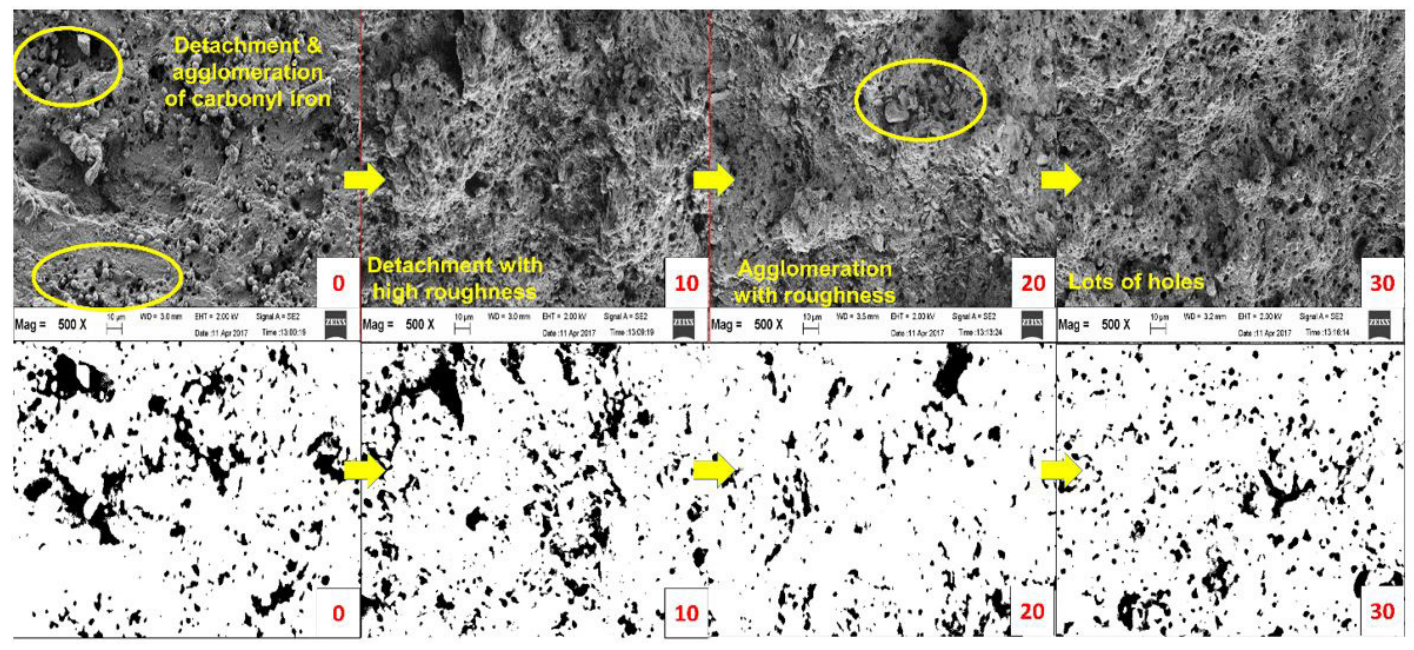

Figure 4. SEM micrographs obtained from tensile fractured surfaces of $\mathrm{CI} / \mathrm{CB}$ hybrid filled $\mathrm{NR} / \mathrm{wNRg}$ composites at $500 \times$ magnifications (CB loadings at 0-30 phr from left to right).

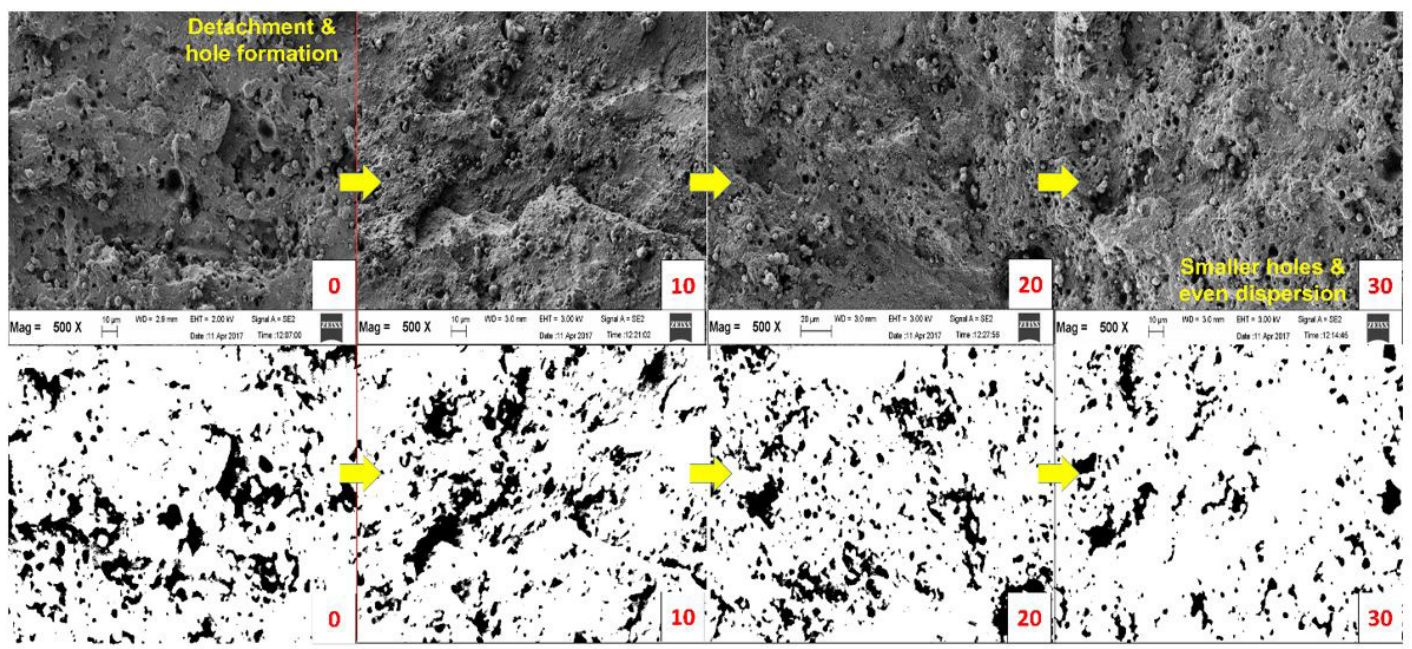

Figure 5. SEM micrographs obtained from tear fractured surfaces of $\mathrm{CI} / \mathrm{CB}$ hybrid filled NR/wNRg composites at 500× magnifications (CB loadings at 0-30 phr from left to right). 
As a result, higher energy is needed to cause a failure to the sample.

Here, both SEM images obtained from tensile and tear fractured surfaces showed very similar existence of CI throughout the matrix. As widely known, two types of MRE can be prepared i.e., Isotropic and Anisotropic MREs ${ }^{[4,5]}$. In this preliminary experiment, Isotropic MRE was prepared, a random suspension of CI particles was then seen without showing specific orientation of CI. As a result, no chain-like columnar structures of magnetic particles are formed within the rubber. Similar observations were reported elsewhere, concerning the existence of magnetic particles in $\mathrm{MRES}^{[11,29]}$.

\subsection{Magnetic property}

The magnetic strength of the samples was measured by placing the probe directly to the rubber sample. The sample was then magnetized with approximate $200 \mathrm{mT}$ prior to measure the magnetic strength. Here, the magnetic property is defined to a measure of the magnetic flux density or magnetic induction of the samples. From the results obtained (see Figure 6), the magnetic strength of the composites decreased with increasing of $\mathrm{CB}$ loading. The magnetic strengths were varied from $0.49,0.34,0.28$ and $0.26 \mathrm{mT}$ respectively. The decrement of magnetic strength is simply due to the nature of $\mathrm{CB}$ which is considered non-magnetic filler ${ }^{[30]}$. Even though the magnetic strength reduced upon inclusion of $\mathrm{CB}$ but the value is still acceptable for MRE. This is clear that simultaneous improvement of mechanical and magnetic properties can be completely achieved by the hybridization with $\mathrm{CB}$. The blockage of $\mathrm{CB}$ to the magnetic

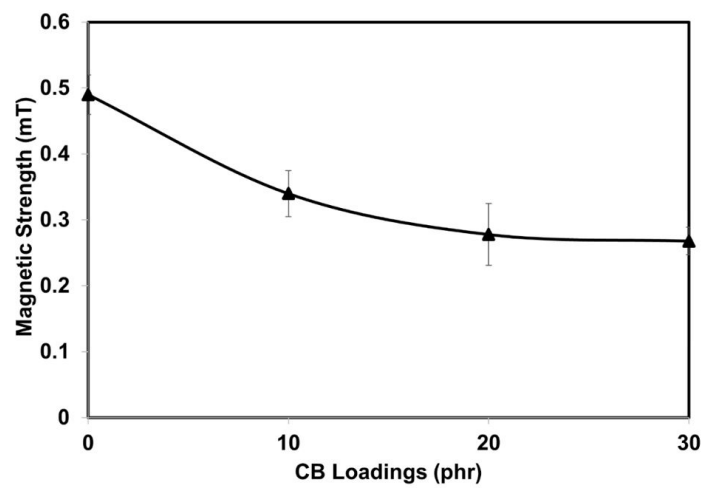

Figure 6. Magnetic strength (mT) of CI/CB hybrid filled NR/wNRg composites. pathway of CI is less enough to provide an acceptable value of the magnetic strength to the composites.

Based on the mechanical strength, swelling, crosslink density and magnetic behaviors of the composites, a schematic illustration representing the reinforcement is proposed in Figure 7. In this model, CI is dispersed in the NR/wNRg composites where it can generate high magnetic strength due to its magnetic behavior in nature of CI. Thus, CI plays an important role in inducing the magnetic pathway to the composite. Upon adding the $\mathrm{CB}$, part of the rubber is trapped inside the aggregate and is shielded from macroscopic deformation due to rubber-filler interaction. These aggregates are dispersed well within a labile rubber matrix and a percolating network. As a result, the penetration of solvent steeply reduces together with higher requirement of energy to break the sample, leading to a significant increase in the tensile strength and tear strength of the composites.

\section{Conclusions}

In this study, NR and wNRg were used as matrices in association with a combination of high magnetic filler (CI) and high reinforcing filler (CB). By varying the volume fraction of hybrid fillers, a new kind of value-added rubber composites with simultaneous improvement of magnetic and mechanical properties were developed. It is interesting to highlight that the tensile strength increased up to $10 \mathrm{phr}$ of $\mathrm{CB}$ whereas the tear strength continuously increased upon the addition of CB. Such observation can be clearly confirmed by SEM images. Shorter scorch times, longer cure time and higher torque difference were found for $\mathrm{CI} / \mathrm{CB}$ hybrid filled NR/wNRg composites at higher loading of $\mathrm{CB}$. As for the magnetic strength of the composites, it was found to decrease with increasing the CB. Lower magnetic strength upon the addition of $\mathrm{CB}$ was due to the less magnetic property of $\mathrm{CB}$ and the blockage of $\mathrm{CB}$ in creating the magnetic pathway of CI. Even though the magnetic strength reduced upon inclusion of $\mathrm{CB}$ but the value is still acceptable for magnetorheological elastomer or MRE. Hybridization of 60/10 phr/phr of CI and CB is highly suggested to gain the synergistic strength and magneticity. The output obtained in this study will give scientific understanding on how these two fillers could influence the properties of MRE, and will provide useful information for preparing MRE in the further stages of this experiment.

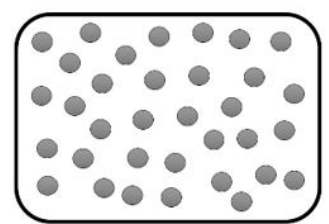

Cl filled NR/wNRg composites

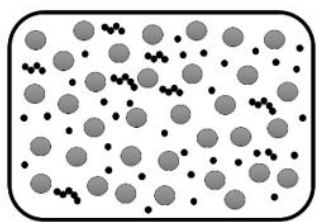

CI/CB hybrid filled NR/wNRg composites

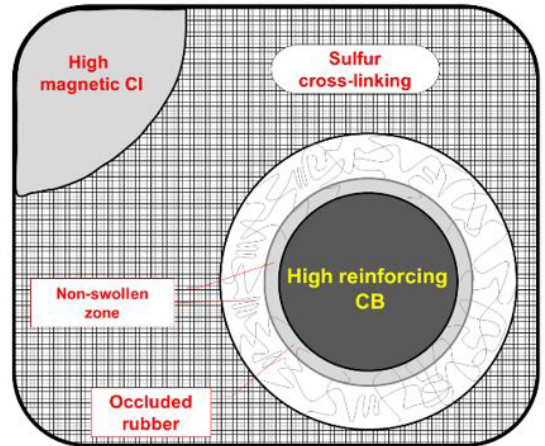

Figure 7. Schematic representation the CI and CB behaviors in CI/CB hybrid filled NR/wNRg composites ${ }^{[19]}$. 


\section{References}

1. Aoyama, T. (2004). Development of gel structured electrorheological fluids and their application for the precision clamping mechanism of aerostatic sliders. CIRP Annals-Manufacturing Technology, 53(1),325-328. http://dx.doi.org/10.1016/S0007-8506(07)60708-2.

2. Pössinger, T., Bolzmacher, C., Bodelot, L., \& Triantafyllidis, N. (2014). Influence of interfacial adhesion on the mechanical response of magneto-rheological elastomers at high strain. Microsystem Technologies, 20(4-5), 803-814. http://dx.doi.org/10.1007/s00542013-2036-0.

3. Japka, J. E. (1988). Microstructure and properties of carbonyl iron powder. Journal of the Minerals Metals \& Materials Society, 40(8), 18-21. http://dx.doi.org/10.1007/BF03258115.

4. Boczkowska, A., Awietjan, S. F., Pietrzko, S. A., \& Kurzydłowski, K. J. (2012). Mechanical properties of magnetorheological elastomers under shear deformation. Composites. Part B, Engineering, 43(2), 636-640. http://dx.doi.org/10.1016/j.compositesb.2011.08.026.

5. Chokkalingam, R., Pandi, R. S., \& Mahendran, M. (2010). Magnetomechanical behavior of $\mathrm{Fe} / \mathrm{PU}$ magnetorheological elastomers. Journal of Composite Materials, 45(15), 1545-1552. http://dx.doi.org/10.1177/0021998310383733.

6. Sun, Y., Zhou, X., Liu, Y., Zhao, G., \& Jiang, Y. (2009). Effect of magnetic nanoparticles on the properties of magnetic rubber. Materials Research Bulletin, 45(17), 878-881. http://dx.doi. org/10.1016/j.materresbull.2010.01.017.

7. Makled, M. H., Matsui, T., Tsuda, H., Mabuchi, H., El-Mansy, M. K., \& Morii, K. (2005). Magnetic and dynamic mechanical properties of barium ferrite natural rubber composites. Journal of Materials Processing Technology, 160(2), 229-233. http://dx.doi. org/10.1016/j.jmatprotec.2004.06.013.

8. Dobrzanski, L. A., Tomiczek, A., Tomiczek, B., Slawska, A., \& Iesenchuk, O. (2009). Polymer matrix composite materials reinforced by $\mathrm{Tb} 0.3 \mathrm{Dy} 0.7 \mathrm{Fe} 1.9$ magnetostrictive particles. Journal of Achievements in Materials and Manufacturing Engineering, 37(1), 16-23.

9. Lokander, M., \& Stenberg, B. (2003). Improving the magnetorheological effect in isotropic magnetorheological rubber materials. Polymer Testing, 22(6), 677-680. http://dx.doi.org/10.1016/S01429418(02)00175-7.

10. Małecki, P., Królewicz, M., Krzak, J., Kaleta, J., \& Pigłowski, J. (2015). Dynamic mechanical analysis of magnetorheological composites containing silica-coated carbonyl iron powder. Journal of Intelligent Material Systems and Structures, 26(14), 1899-1905. http://dx.doi.org/10.1177/1045389X15581522.

11. Shuib, R. K., Pickering, K. L., \& Mace, B. R. (2015). Dynamic properties of magnetorheological elastomers based on iron sand and natural rubber. Journal of Applied Polymer Science, 132(8), 41506. http://dx.doi.org/10.1002/app.41506.

12. Soloman, M., Kurian, P., Anantharaman, M., \& Joy, P. (2005). Cure characteristics and dielectric properties of magnetic composites containing strontium ferrite. Journal of Elastomers and Plastics, 37(2), 109-121. http://dx.doi.org/10.1177/0095244305046488.

13. Nabil, H., \& Ismail, H. (2014). Fatigue life, thermal analysis and morphology of Recycled Poly(Ethylene Terephthalate)/commercial fillers hybrid filled natural rubber composites. Progress in Rubber, Plastics and Recycling Technology, 30(2), 115-128. http://dx.doi. org/10.1177/147776061403000204.

14. Sumita, M., Sakata, K., Asai, S., Miyasaka, K., \& Nakagawa, H. (1991). Dispersion of fillers and the electrical conductivity of polymer blends filled with carbon black. Polymer Bulletin, 25(2), 265-271. http://dx.doi.org/10.1007/BF00310802.

15. Chen, L., Gong, X. L., \& Li, W. H. (2008). Effect of carbon black on the mechanical performances of magnetorheological elastomers. Polymer Testing, 27(3), 340-345. http://dx.doi.org/10.1016/j. polymertesting.2007.12.003.
16. Guyomar, D., Matei, D. F., Guiffard, B., Le, Q., \& Belouadah, R. (2009). Magnetoelectricity in polyurethane films loaded with different magnetic particles. Materials Letters, 63(6-7), 611-613. http://dx.doi.org/10.1016/j.matlet.2008.11.058.

17. Sun, T. L., Gong, X. L., Jiang, W. Q., Li, J. F., Xu, Z. B., \& Li, W. H. (2008). Study on the damping properties of magnetorheological elastomers based on cis-polybutadiene rubber. Polymer Testing, 27(4), 520-526. http://dx.doi.org/10.1016/j.polymertesting.2008.02.008.

18. Wang, Y., Hu, Y., Deng, H., Gong, P. G., Jiang, W., \& Chen, Z. (2006). Magnetorheological elastomers based on isobutyleneisoprene rubber. Polymer Engineering and Science, 46(3), 264-268. http://dx.doi.org/10.1002/pen.20462.

19. Hayeemasae, N., \& Ismail, H. (2019). Curing and swelling kinetics of new magnetorheological elastomer based on natural rubber/waste natural rubber gloves composites. Journal of Elastomers and Plastics, 51(7-8), 583-602. http://dx.doi.org/10.1177/0095244318803987.

20. Flory, P. J., \& Rehner, J. Jr (1943). Statistical mechanics of cross-linked polymer networks I. Rubberlike elasticity. The Journal of Chemical Physics, 11(11), 512-520. http://dx.doi. org/10.1063/1.1723791.

21. Medalia, A. I. (1978). Effect of carbon black on dynamic properties of rubber vulcanizates. Rubber Chemistry and Technology, 51(3), 437-523. http://dx.doi.org/10.5254/1.3535748.

22. Qing, Y., Min, D., Zhou, Y., Luo, F., \& Zhou, W. (2015). Graphene nanosheet-and flake carbonyl iron particle-filled epoxy-silicone composites as thin-thickness and wide-bandwidth microwave absorber. Carbon, 86(1), 98-107. http://dx.doi.org/10.1016/j. carbon.2015.01.002.

23. Hamilton, R., \& Crosser, O. (1962). Thermal conductivity of heterogeneous two-component systems. Industrial \& Engineering Chemistry Fundamentals, 1(3), 187-191. https://doi.org/10.1021/ i160003a005

24. Gehman, S. (1967). Heat transfer in processing and use of rubber. Rubber Chemistry and Technology, 40(1), 36-99. http://dx.doi. org/10.5254/1.3539047.

25. Ismail, H., Rosnah, N., \& Rozman, H. (1997). Curing characteristics and mechanical properties of short oil palm fibre reinforced rubber composites. Polymer, 38(16), 4059-4064. http://dx.doi.org/10.1016/ S0032-3861(96)00993-7.

26. Wolff, S., \& Wang, M. J. (1992). Filler-elastomer interactions. Part IV. The effect of the surface energies of fillers on elastomer reinforcement. Rubber Chemistry and Technology, 65(2), 329-342. http://dx.doi.org/10.5254/1.3538615.

27. Bigg, D. M. (1987). Mechanical properties of particulate filled polymers. Polymer Composites, 8(2), 115-122. http://dx.doi. org/10.1002/pc.750080208.

28. Baccaro, S., Cataldo, F., Cecilia, A., Cemmi, A., Padella, F., \& Santini, A. (2003). Interaction between reinforce carbon black and polymeric matrix for industrial applications. Nuclear Instruments \& Methods in Physics Research. Section B, Beam Interactions with Materials and Atoms, 208, 191-194. http://dx.doi.org/10.1016/ S0168-583X(03)00638-4.

29. Khimi, S. R., \& Pickering, K. L. (2015). Comparison of dynamic properties of magnetorheological elastomers with existing antivibration rubbers. Composites. Part B, Engineering, 83(1), 175-183. http://dx.doi.org/10.1016/j.compositesb.2015.08.033.

30. Jovanović, V., Samaržija-Jovanović, S., Budinski-Simendić, J., Marković, G., \& Marinović-Cincović, M. (2013). Composites based on carbon black reinforced NBR/EPDM rubber blends. Composites. Part B, Engineering, 45(1), 333-340. http://dx.doi. org/10.1016/j.compositesb.2012.05.020.

Received: Feb. 03, 2020

Revised: June 08, 2020

Accepted: June 29, 2020 